\title{
MATLAB Based Model for Analysis of the Effect of Equivalent Circuit Parameters of an Asynchronous Motor on its Dynamic Characteristics
}

\author{
Bhaskar Lodh ${ }^{1}$, Writwik Balow ${ }^{2}$ \\ ${ }^{1,2}$ (Department of Electrical Engineering, Bengal Institute of Technology \& Management, West Bengal, India)
}

\begin{abstract}
A poly phase asynchronous motor - for instance, an induction motor finds application in several areas due to its reliability, robustness, low maintenance and a very competitive pricing. This paper addresses the impact of stator and rotor parameters of an induction motor in its dynamic characteristics using a MATLAB / SIMULINK based model. This analysis helps in determining the stator and rotor circuit resistance and inductances to reduce steady state time and minimize jerks during starting of the motor.
\end{abstract}

Keywords: Asynchronous Motor, MATLAB, Modeling, SIMULINK, Speed-Torque Characteristics

\section{Introduction}

A three phase squirrel cage induction motor is a simple, robust and efficient Asynchronous motor. It's often a natural choice as a drive for industries. It has a self starting torque and reasonably good power factor at full load operation. Three-phase induction motors are the "workhorses" of industry and are the most widely used electrical machines. Due its simple structure and reliability, these motors are used for many purposes such as: pumps, blowers, fans, compressors, transportation, etc. In this paper a SIMULINK model of the asynchronous motor has been presented, taking the rotor as a reference frame. It will be shown that the inductance of both the stationary and rotating body of the motor should be kept low to reduce the steady state time and also to reduce jerks during starting of the motor.

\section{Analysis Using Matlab -Simulink Environment}

Matlab/Simulink is a systems simulator furnished by The MathWorks, Inc. For simulation of electrical circuits, power system block sets are used which incorporates libraries of electrical blocks and analysis tools which are used to convert electrical circuits into Simulink diagrams. The electrical blocks are electrical models such as different electrical machines (ac and dc), current and voltage sources, and different electric elementssuch as RLC load, breaker etc., power electronic switches, connectors, and sensors for measurement purpose.

There are several MATLAB functions and toolboxes available in MATLAB environment for processing and plotting of waveforms from analyzed data. Simulink provides a stage for professionals to plan, analyze, design, simulate, test and implement different types of systems. Simulink-Matlab combination is very functional for developing algorithms, creation of block diagrams and analysis of different simulation based designs.

\section{Three Phase Asynchronous Motor Test System}

Here a SIMULINK model of three-phase squirrel cage asynchronous motor is shown, with a constant input mechanical torque. It is fed from a $50 \mathrm{~Hz}, 400$ Volt supply. Stator and rotor winding are connected in star to an internal neutral point. In this paper, the rotor and stator current, speed, electromagnetic torque and torque speed characteristics of the motor is shown, taking different values of rotor and stator resistance and impedances. In this model a Three-phase programmable voltage source has been used which is capable of generating a three-phase sinusoidal voltage with time varying parameters. The Asynchronous Machine block is available under machine block in SimPowerSystem library. It operates in either generator or motor modeindicated by the sign of mechanical input torque $\left(\mathrm{T}_{\mathrm{m}}\right)$. The machine acts as a motor, if $\mathrm{T}_{\mathrm{m}}$ is positive. Else, it will be treated as a generator. 


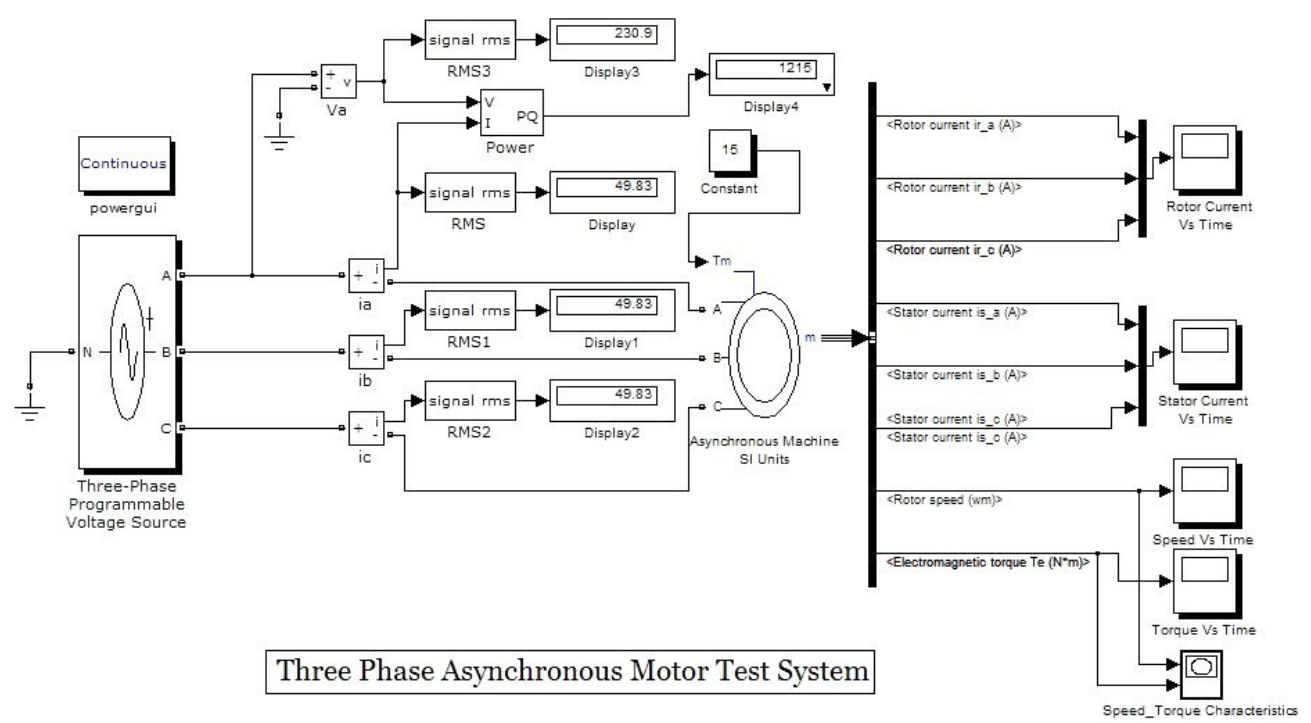

III. Table 1 : Equivalent Circuit Parameters For The Induction Motor Tested

\begin{tabular}{|l|c|c|c|c|c|c|c|}
\hline & $\begin{array}{c}\text { Voltage } \\
\text { (Line to Line) } \\
(\mathbf{V})\end{array}$ & $\begin{array}{c}\text { Frequency } \\
(\mathbf{H z})\end{array}$ & $\begin{array}{c}\text { Rotor } \\
\text { Resistance } \\
\text { (Ohm) }\end{array}$ & $\begin{array}{c}\text { Rotor } \\
\text { Inductance } \\
\text { (Henry) }\end{array}$ & $\begin{array}{c}\text { Stator } \\
\text { Resistance } \\
\text { (Ohm) }\end{array}$ & $\begin{array}{c}\text { Stator } \\
\text { Inductance } \\
\text { (Henry) }\end{array}$ & $\begin{array}{c}\text { Mutual } \\
\text { Inductance } \\
\text { (Henry) }\end{array}$ \\
\hline $\begin{array}{l}\text { Test } \\
1\end{array}$ & 400 & 50 & 0.05030 & 0.000698 & 0.08115 & 0.0000488 & 0.034 \\
\hline $\begin{array}{l}\text { Test } \\
2\end{array}$ & 400 & 50 & 0.05087 & 0.000724 & 0.08115 & 0.000733 & 0.034 \\
\hline $\begin{array}{l}\text { Test } \\
3\end{array}$ & 400 & 50 & 0.05067 & 0.000765 & 0.08126 & 0.002564 & 0.034 \\
\hline
\end{tabular}

IV. Result Of Simulation

Test 1

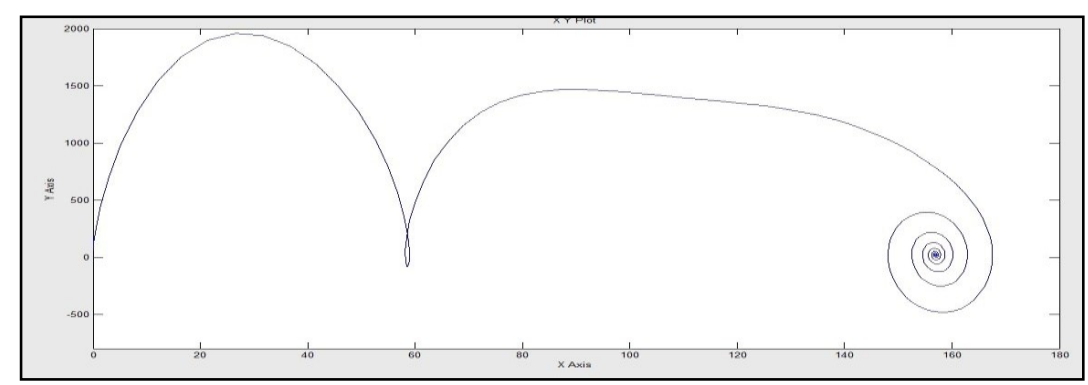

Fig 1 : Torque Speed Characteristics

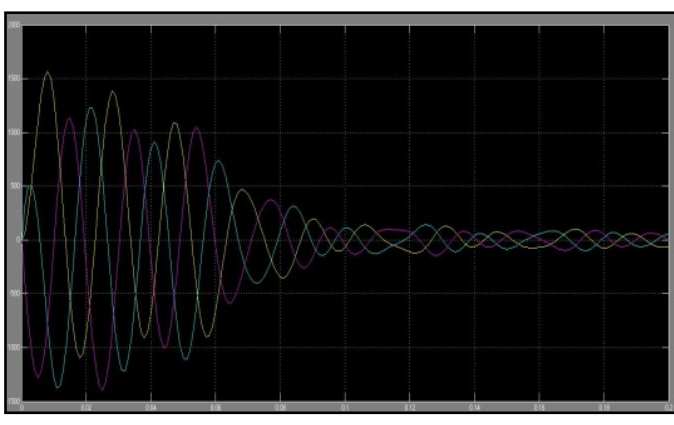

Fig 2 : Stator Current Vs Time Graph

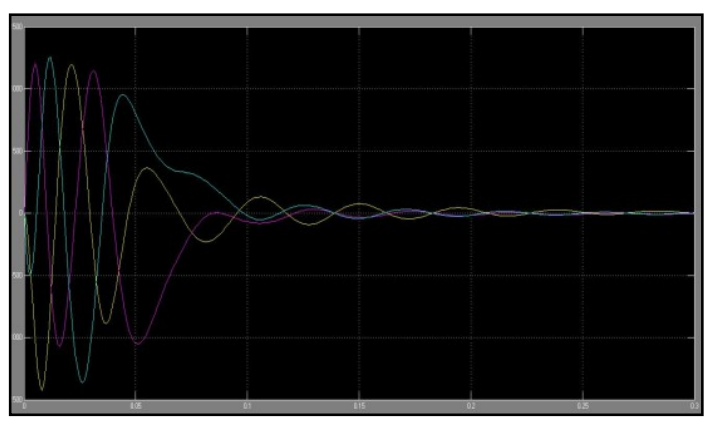

Fig 3 : Rotor Current Vs Time Graph 


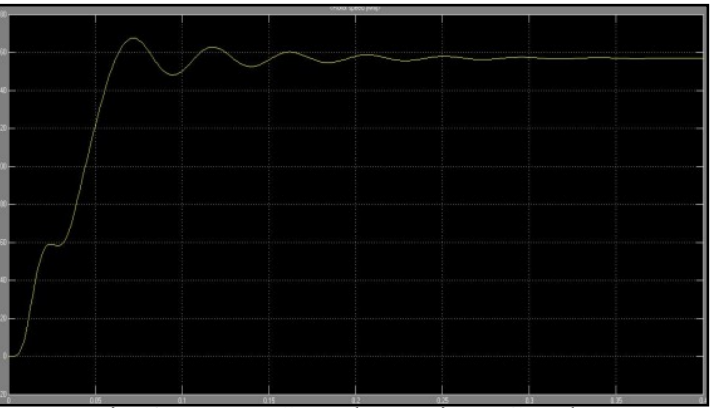

Fig 4 : Rotor Speed Vs Time Graph

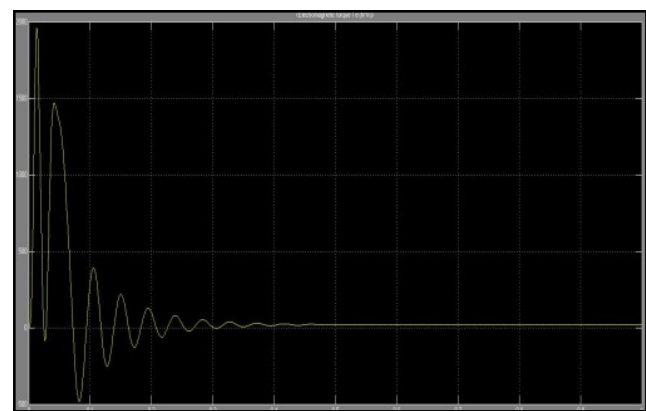

Fig 5: Torque Vs Time Graph

Test 2

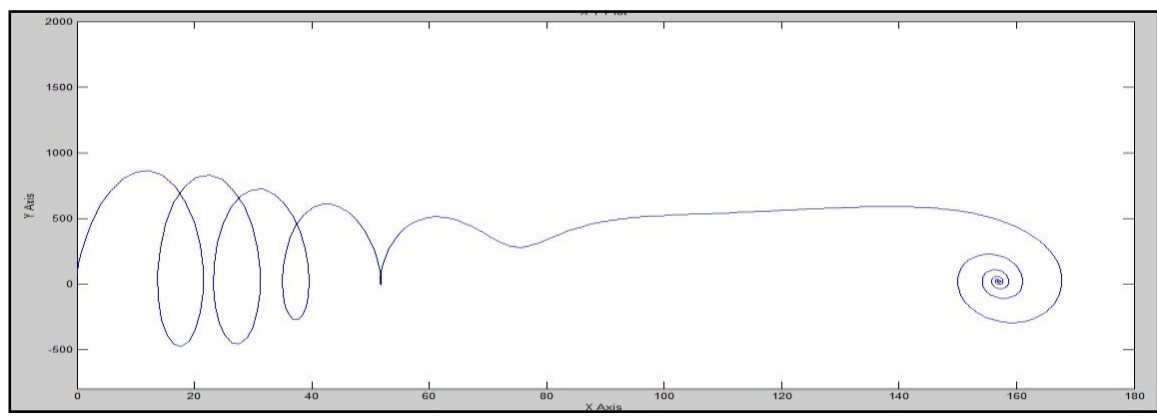

Fig 6: Torque Speed Characteristics

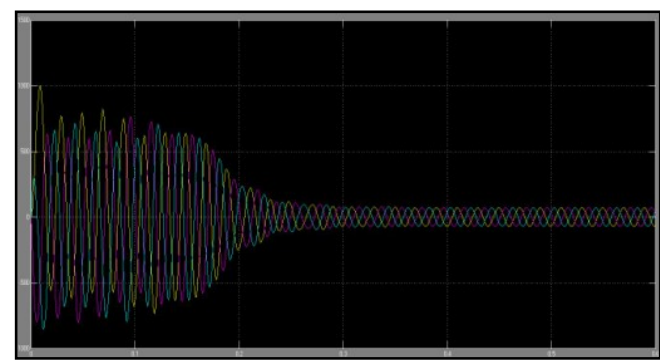

Fig 7 : Stator Current Vs Time Graph

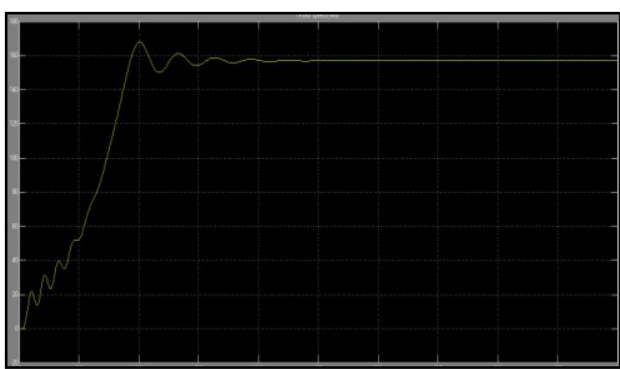

Fig 9 : Rotor Speed Vs Time Graph

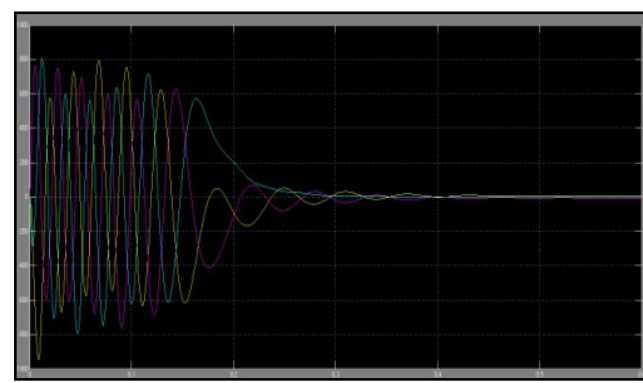

Fig 8 : Rotor Current Vs Time Graph

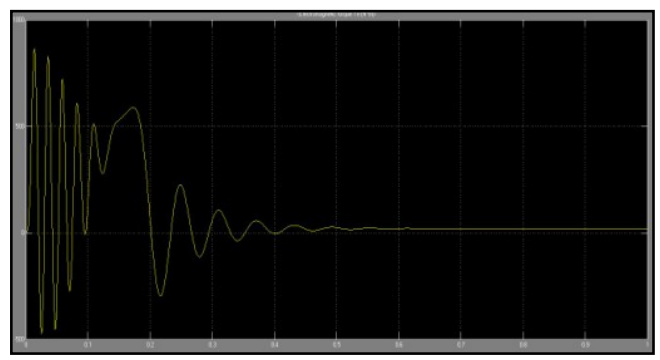

Fig 10 : Torque Vs Time Graph

Test 3

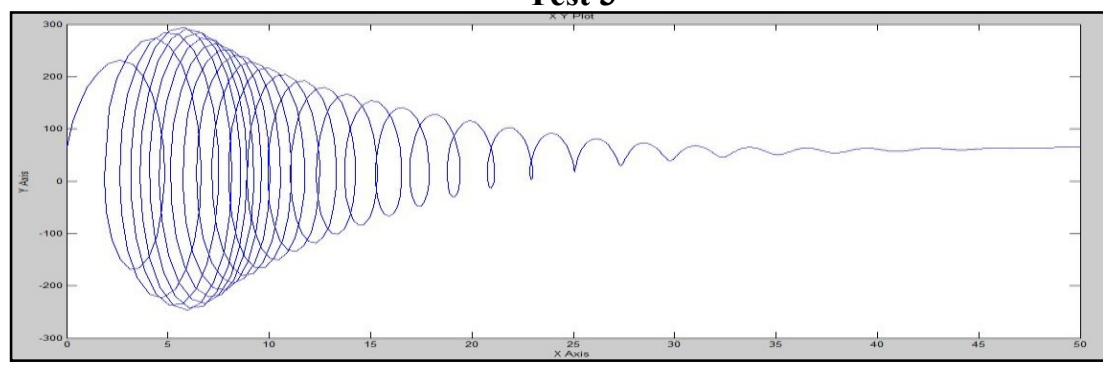

Fig 11 : Torque Speed Characteristics

www.iosrjournals.org 


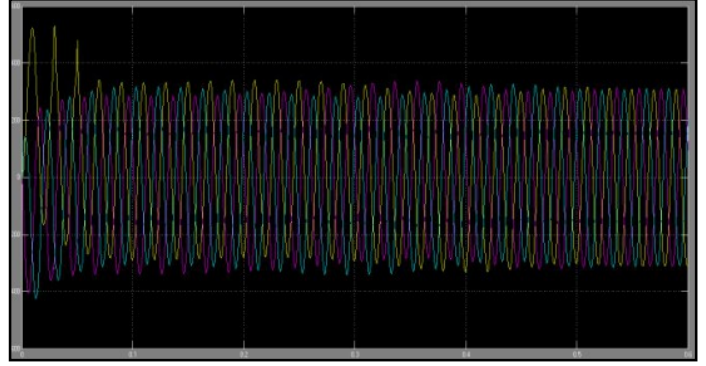

Fig 12 : Stator Current Vs Time Graph

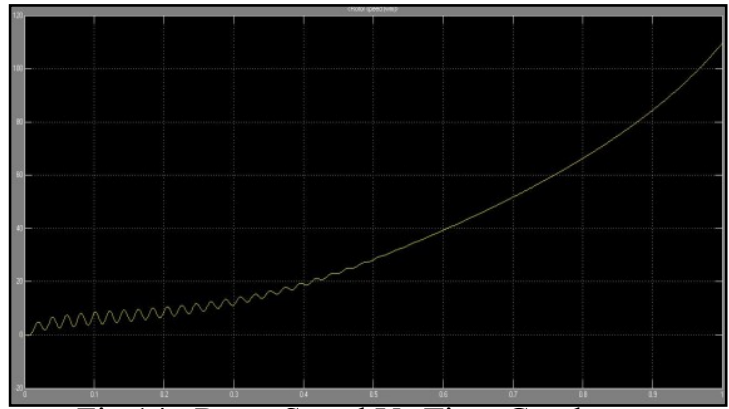

Fig 14 : Rotor Speed Vs Time Graph

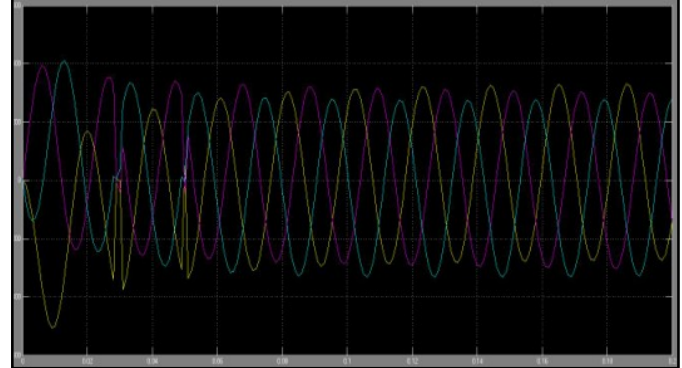

Fig 13 : Rotor Current Vs Time Graph

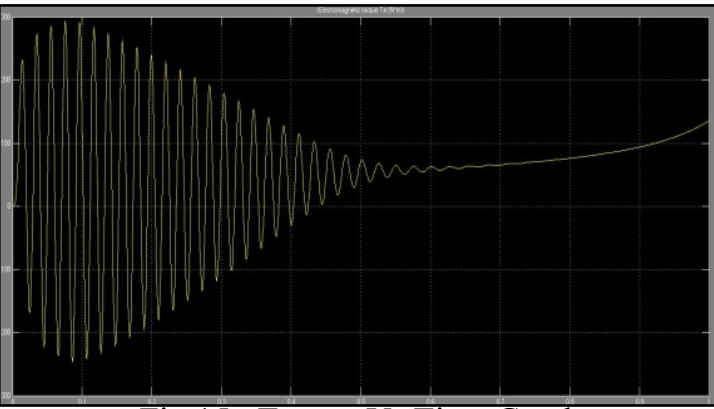

Fig 15: Torque Vs Time Graph

\section{Conclusion}

Above Test result shows that a small variation of resistance of the rotor has a little impact on its dynamic performance. Although, it can be shown that when rotor resistance increases, the initial oscillations of the motor parameters gets reduced, i.e. motor will start with lesser jerks. On increasing the Stator inductance the transients lasted for very long period. The machine took more time to acquire its steady state speed, steady state current and steady state torque. Also the start was a bit jerky and the current drawn from the supply was excessively high. Therefore, to achieve satisfactory performance of the motor, the stator parameters (both its resistance and inductance) should be kept as low as possible.

\section{References}

[1] S.Ayasun,C.O.Nwankpa, Induction Motor Tests Using MATLAB/Simulink and Their Integration into Undergraduate Electrical Machinery Courses, IEEE TRANSACTIONS ON EDUCATION, VOL. 48, NO. 1, FEBRUARY 2005

[2] A A Ansari, D M Deshpande, Mathematical Model of Asynchronous Machine in MATLAB Simulink, A. Ansari et. al. / International Journal of Engineering Science and Technology ,Vol. 2(5), 2010, 1260-1267

[3] M Blödt, P Granjon, B Raison,Member,G Rostaing, Models for Bearing Damage Detection in Induction Motors Using Stator Current Monitoring, IEEE TRANSACTIONS ON INDUSTRIAL ELECTRONICS, VOL. 55, NO. 4, APRIL 2008

[4] M K Arya, Dr.S Wadhwani, Transient Analysis of Three Phase Squirrel Cage Induction Machine using Matlab, Mukesh Kumar Arya, Dr.Sulochana Wadhwani / International Journal of Engineering Research and Applications (IJERA) ISSN: 2248-9622, Vol. 1, Issue 3, pp.918-922.

[5] I.J. Nagrath, D.P. Kothari, Electrical Machines (New Delhi, Tata McGraw-Hill Publishing company Limited, 2003)

[6] The MathWorks, Inc, Simulink- Dynamic System Simulation for Matlab (Natick, M A, USA, The MathWorks, Inc, 2000) 